\title{
Effect of oxidation and annealing temperature on optical and structural properties of $\mathrm{SnO}_{2}$
}

\author{
M ZARRINKHAMEH ${ }^{1}$, A ZENDEHNAM ${ }^{1}$, S M HOSSEINI $^{2}$, N ROBATMILI $^{1}$ and \\ M ARABZADEGAN ${ }^{1}$ \\ ${ }^{1}$ Thin Film Laboratory, Department of Physics, Faculty of Science, Arak University, Arak 38156-8-8349, Iran \\ ${ }^{2}$ Department of Chemical Engineering, Faculty of Engineering, Arak University, Arak 38156-8-8349, Iran
}

MS received 3 October 2012; revised 11 April 2013

\begin{abstract}
Tin oxide thin films were deposited on glass substrate with $100 \mathrm{~nm}$ thickness of Sn, which was coated by magnetron sputtering followed by thermal oxidation at different temperatures. The effect of oxidation temperature on the optical and structural properties of $\mathrm{SnO}_{2}$ films were investigated. Higher transmittance, lower absorption and lesser structural defects were obtained at higher temperatures. Optical bandgap increases with temperature, while the Urbach energy showed reduction. The $\mathrm{X}$-ray diffraction studies showed that at lower temperatures $\left(300,350{ }^{\circ} \mathrm{C}\right)$, a combined phase of $\mathrm{SnO}$ and $\mathrm{SnO}_{2}$ was obtained, while at higher temperatures $\left(400,450{ }^{\circ} \mathrm{C}\right)$, a nearly polycrystalline $\mathrm{SnO}_{2}$ film with preferred orientation of (101) was produced. Annealing of the samples at $500-650{ }^{\circ} \mathrm{C}$ caused the transmittance and optical bandgap increased, while the absorption decreased. Reduction of the Urbach energy after annealing could be attributed to the reduction of the degree of thermal disorder. AFM studies showed that although the thin films were annealed under similar condition, their roughness was not similar because of different oxidation temperatures, which means that initial oxidation temperature played an important role on surface uniformity of $\mathrm{SnO}_{2}$ thin films.
\end{abstract}

Keywords. $\mathrm{SnO}_{2}$ thin films; optical properties; optical bandgap; Urbach energy; surface roughness; XRD.

\section{Introduction}

Tin oxide belongs to a class of materials that have suitable electrical conductivity and high optical transparency, thus plays an important role for optoelectronic applications. $\mathrm{SnO}_{2}$ as an oxide, exhibits sensitivity towards oxidizing by variation of its electrical properties. The surface and materials properties of $\mathrm{SnO}_{2}$ should be discussed in context of its three major applications. The applications are: (i) as a transparent conducting oxide (TCO), (ii) as an oxidation catalyst and (iii) as a solid state gas sensing material (Matthias Batzill and Ulrike Diebold 2005). As a consequence, it can be attractive because of its wide application in various fields like photovoltaic solar cells (Goetzberger and Hebling 2000), liquid crystal displays (Kim et al 1999a, b), gas sensors (Nelli et al 2000), thin film resistors (Kane et al 1976) etc.

$\mathrm{SnO}_{2}$ is a wide bandgap oxide semiconductor with a rutile-type tetragonal crystalline structure according to PCPDFWIN (JCPDS 2002 International Center for Diffraction Data). Pure $\mathrm{SnO}_{2}$ films have poor electrical conductivity, instead they are highly transparent in visible and near infrared region. However, its low conductivity

\footnotetext{
*Author for correspondence (zarrinkhameh55@yahoo.com)
}

could be improved by doping (Sung et al 2011). The exciton energy of $\mathrm{SnO}_{2}$ is $130 \mathrm{meV}$, whose importance is observable in manufacturing of plasmon lasers (Span et al 2006).

Most of the researches on tin oxide are focused on doped $\mathrm{SnO}_{2}$ with different elements (Jochan Joseph et al 2007), but at the present work, pure tin oxide is produced. The properties of $\mathrm{SnO}_{2}$ films such as its transmittance, optical bandgap, absorption coefficient, surface structure, etc. can be varied by preparation method. $\mathrm{SnO}_{2}$ has been produced by several methods such as chemical vapour deposition (Kane et al 1976; Span et al 2006), spray pyrolysis (Rohatgi et al 1974; Kim and Laitinen 1975), reactive rf sputtering (Watanabe 1970), magnetron sputtering (Ryzhikov et al 2002), d.c. glow discharge (Carlson 1975), sol-gel techniques (Varghese and Malhotra 2000; Sunita Mishra et al 2002), vacuum evaporations (Lehmann and Widmer 1975), but among these techniques, magnetron sputtering is considerable, because of some advantages like film uniformity, control of deposition rate, high purity and good adhesion of layer to substrate. Also, this method can be extended to industrial scales for device fabrication. In this research, magnetron sputtering was used for deposition of Sn. Thermal oxidation is rarely used in preparation of $\mathrm{SnO}_{2}$, but in this work, tin oxide has been produced by the above method. 
One of the important parameters for the exact characterization of a semiconductor is the optical bandgap energy. According to the literature, depending on whether $\alpha, \alpha^{1 / 2}$ or $\alpha^{2}$ (Melsheimerand Ziegler 1985) (where $\alpha$ is the absorption coefficient), the bandgap energies for nonsingle-crystal tin oxide thin films lie between 2.25 and $4.45 \mathrm{eV}$ (Melsheimer and Ziegler 1985; Shadia and Riyad 2011). In this research, we have found optical bandgap by considering $\alpha^{2}$. An important quantity which describes the structural and thermal disorder of a semiconductor is the Urbach energy $\left(E_{\mathrm{u}}\right)$. In recent decades, only few works were found to investigate the Urbach tail in $\mathrm{SnO}_{2}$ thin films and its variations with deposition parameters (Melsheimer and Ziegler 1985; Shadia and Riyad 2011). In the present work, $E_{\mathrm{u}}$ and its dependency on oxidation temperature and annealing temperature of $\mathrm{SnO}_{2}$ thin films were studied. In addition, the point called 'convergent point' which exhibits the energy bandgap of a semiconductor at zero temperature, was obtained for $\mathrm{SnO}_{2}$ thin films.

\section{Experimental}

To produce tin oxide thin film samples, a vacuum system with base pressure of $10^{-6}$ mbar was employed (HINDHI-VAC, 12" MSPT). A circular flat disc (thickness $3 \mathrm{~mm}$ and diameter $125 \mathrm{~mm}$ ) of pure $\mathrm{Sn}$ (99/9\%) was used as the sputtering target. For plasma formation, research grade argon (99.99\% purity) at a pressure of $2 \times 10^{-2}$ mbar was used. All the samples were deposited under similar experimental conditions. Circular glass substrate (white glass which has higher melting and softening point and can stand easily up to $700{ }^{\circ} \mathrm{C}$ ) were used, and just before using them, a 3-step ultrasonic cleaning process (acetone, methanol and deionized water) was carried out. During deposition of $\mathrm{Sn}$, the substrate temperature was monitored by an exact digital thermocouple (300 K). The coating rate and film thickness were measured by a vibrating quartz crystal thickness monitor. Before Sn deposition, the plasma discharge was run for a few minutes (5-10 $\mathrm{min})$, and to ensure a high purity coating, the produced plasma was checked by a spectrometer with high resolving power. When Sn and Ar (atoms and ions) were the only line spectra presented in vacuum system, deposition of tin on glass was started, and no band spectrum due to contamination was detected. Also to obtain an uniform layer with proper deposition rate, the optimum distance between target and substrate was selected $(12 \mathrm{~cm})$. In order to investigate the effect of oxidation temperature and annealing temperature on the structural and optical properties of $\mathrm{SnO}_{2}$ thin films, two steps of sample preparations were carried out. At first, $100 \mathrm{~nm}$ thickness of Sn was deposited on four glass substrates A, $\mathrm{B}, \mathrm{C}$ and $\mathrm{D}$, after that, samples were transferred to the oven for oxidation in air, forming $\mathrm{SnO}_{2}$ at 300 (A),
350(B), $400(\mathrm{C}), 450{ }^{\circ} \mathrm{C}$ (D) for $10 \mathrm{~min}$. Then, their transmittance, absorption coefficient, optical bandgap and the Urbach energy were investigated. In second step, all the samples were annealed at temperature range of 500 $650{ }^{\circ} \mathrm{C}$.

For optical measurements a double beam spectrophotometer (Camspec model 350), with wavelength range of 200-1100 nm was used, thus, transmittance $(T)$, absorption coefficient $(\alpha)$ and energy bandgap $\left(E_{\mathrm{g}}\right)$ of samples were obtained. To investigate the morphology and surface roughness of the samples, atomic force microscopic (AFM, Park Scientific Instrument, Auto Probe model CP) was used and for characterization of the produced thin films, X-ray diffraction (XRD, Philips PW $3373, \lambda=1.54 \mathrm{~nm}$ ) analysis was utilized.

\section{Results and discussion}

\subsection{Effect of oxidation temperature}

At first, it should be noted that in order to avoid the discontinuity of thin films and also to elude of crystal defects, the thickness of $100 \mathrm{~nm}$ was selected for deposition of $\mathrm{Sn}$ thin films. To study the effect of oxidation temperature on optical properties of the produced thin films, their transmittance was measured. Figure 1 shows the optical transmittance of the $\mathrm{SnO}_{2}$ films. It is evident that the optical transmittance increases by raising the oxidation temperature. This indicates that the oxidation may not accomplished properly at lower temperatures (300 and $350{ }^{\circ} \mathrm{C}$ ). Also, figure 1 shows that sample D which was oxidized at the highest temperature $\left(450^{\circ} \mathrm{C}\right)$, starts to transmit at lower wavelengths. In addition, as it is expected, higher oxidation temperature produces layers

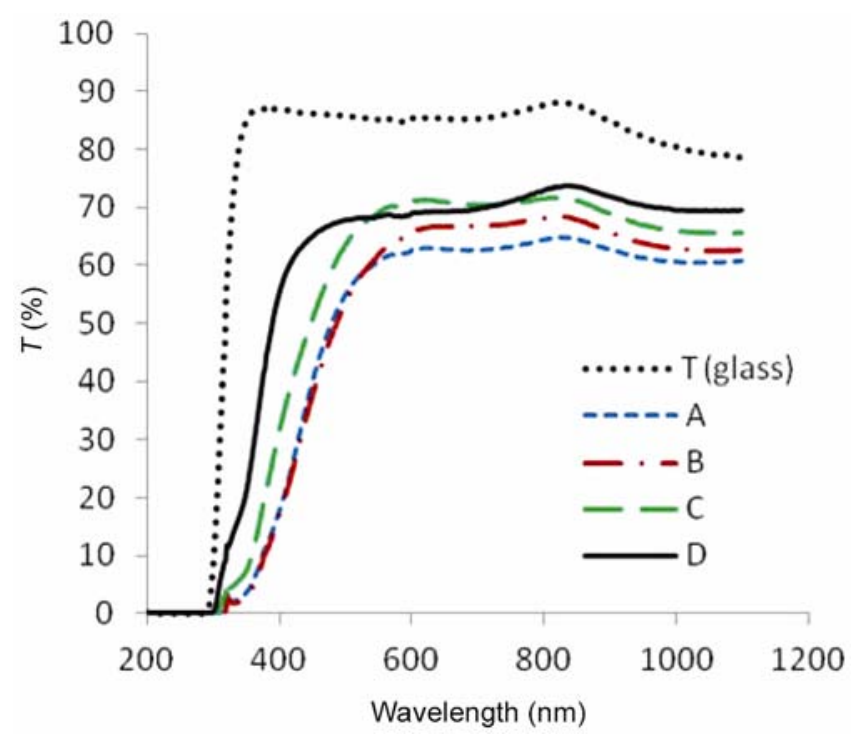

Figure 1. Transmittance spectra of $\mathrm{SnO}_{2}$ thin films for various oxidation temperatures. 
with more transparency. The graph of absorption coefficient vs wavelength (figure 2) coincides with the result of transmittance of layers. According to figure 2, sample D has the lowest absorption, which means higher transmittance.

The optical bandgap of the films is determined by the following relationship (Li et al 2007):

$$
\alpha h v=A\left(h v-E_{\mathrm{g}}\right)^{m} .
$$

In (1), $A$ is energy-independent constant, $E_{\mathrm{g}}$ denotes the optical bandgap, $m$ is a constant, which is $1 / 2$ for direct bandgap semiconductors and $\alpha$ denotes the absorption coefficient, which is determined from (2) (Sreetama Dutta et al 2009):

$$
\alpha=\frac{1}{d} \ln \left(\frac{t_{0}}{t}\right) .
$$

where $t$ and $t_{0}$ are the transmittance of the $\mathrm{SnO}_{2}$ sample, and the substrate (glass) without $\mathrm{SnO}_{2}$ coating, respectively and $d$ the film thickness. By plotting of $(\alpha h v)^{2}$ vs $h v$ and finding the intercept of curve with $h v$ axis, optical bandgap of thin films was determined. Accordingly, $E_{\mathrm{g}}$ of thin films were found to be 3.93, 3.91, 4.04 and $4.11 \mathrm{eV}$ for samples A, B, C and D, respectively (figure 3 ). These $E_{\mathrm{g}}$ are higher than the values of optical bandgap of $\mathrm{SnO}_{2}$ reported by Melsheimer and Ziegler (1985) which were obtained for different substrate temperatures (considering $(\alpha h v)^{1 / 2}$ and $\left.(\alpha h v)^{1 / 3}\right)$ and are close to the values achieved by Shadia and Riyad (2011), who got the energy bandgap of 3.753-4.082 eV for fluorine-doped $\mathrm{SnO}_{2}$ thin films prepared by the spray pyrolysis technique. In addition, as the results show, $E_{\mathrm{g}}$ of layers are very close together. This result agrees with research of (Khan et al 2009). They showed that rf sputtered $\mathrm{SnO}_{2}$ films have very small variations in bandgap energy up to $500{ }^{\circ} \mathrm{C}$.

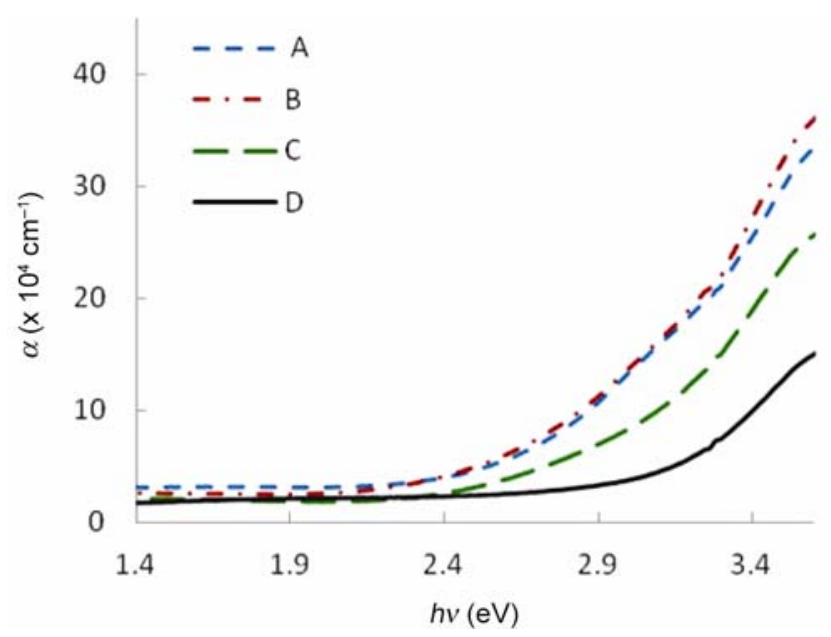

Figure 2. Plot of $\alpha$ vs $h v$ for tin oxide films for different oxidation temperatures.
One of the ways, one can study the quality of a semiconductor thin films, is to investigate the Urbach energy and its variations with deposition parameters, so the Urbach energy of the samples was determined.

In the exponential (absorption) edge region, the Urbach rule is expressed as (Urbach 1953)

$$
\alpha=\alpha_{0} \exp \left(\frac{h v}{E_{\mathrm{u}}}\right),
$$

where $\alpha_{0}$ is a constant, $h v$ denotes the photon energy and $E_{\mathrm{u}}$ is the Urbach energy, which characterizes the slope of the exponential edge. Equation (3) describes the optical transition between the occupied states in the valence band tail to the unoccupied states of the conduction band edge.

To obtain the value of $E_{\mathrm{u}}$, the graph of $\ln (\alpha)$ against $h v$ is plotted (for $h v<E_{\mathrm{g}}$ ), which is linear, and the Urbach energy can be calculated from the inverse slope. Figure 4 shows relation between $\ln (\alpha)$ and $h v$ for sample $\mathrm{D}$ as an example. The values of $E_{\mathrm{u}}$ for thin films $\mathrm{A}, \mathrm{B}, \mathrm{C}$ and D were found to be 352, 460, 245, $127 \mathrm{meV}$, respectively. Because the Urbach energy indicates the structural disorder of a semiconductor, these values show that except sample B, the layers which oxidized at higher temperatures, have lower Urbach energy and as a consequence, lower defects. This result can be attributed to degree of crystallinity of layers; lower oxidation temperature leads to an amorphous structure, whereas higher oxidation temperature corresponds to a layer with rather high degree of crystallinity. XRD studies verify this claim. Figure 5(a,b) (XRD diffraction) shows that at low oxidation temperatures $\left(300\right.$ and $350{ }^{\circ} \mathrm{C}$ ), thin films are composed of $\mathrm{SnO}$ (JCPDS no. 06-0395) and $\mathrm{SnO}_{2}$ (JCPDS no. 41-1445) phase. As the temperature increases $\left(400{ }^{\circ} \mathrm{C}\right)$, the peaks of $\mathrm{SnO}_{2}$ become sharper, specially (101) peak. Finally at $450{ }^{\circ} \mathrm{C}$, a nearly polycrystalline $\mathrm{SnO}_{2}$ thin film, with preferred orientation of (101) is formed. This higher intensities lead to larger grain size. Also it is clear from figure 5 that there is a peak next to the (101), which may be attributed to $\mathrm{Sn}_{2} \mathrm{O}_{3}$ (JCPDS no. 25-1259) or $\mathrm{Sn}_{3} \mathrm{O}_{4}$ (JCPDS no. 16-757) phase (Choi et al 1997; Pana and Fu 2001).

\subsection{Effect of annealing temperature}

In order to know how annealing temperature affects the optical properties of $\mathrm{SnO}_{2}$ layers, all the samples were heated at temperatures 500,550,600, $650^{\circ} \mathrm{C}$. Figure 6 shows the optical transmittance of thin films for different annealing temperatures. In the case of sample A, which was oxidized at $300{ }^{\circ} \mathrm{C}$, the transparency varies more than the other three samples. Also, it can be seen that at $650{ }^{\circ} \mathrm{C}$, the same transmittance is obtained roughly for all the four samples, which means that annealing temperature of $650{ }^{\circ} \mathrm{C}$ might be sufficient to get a good and 

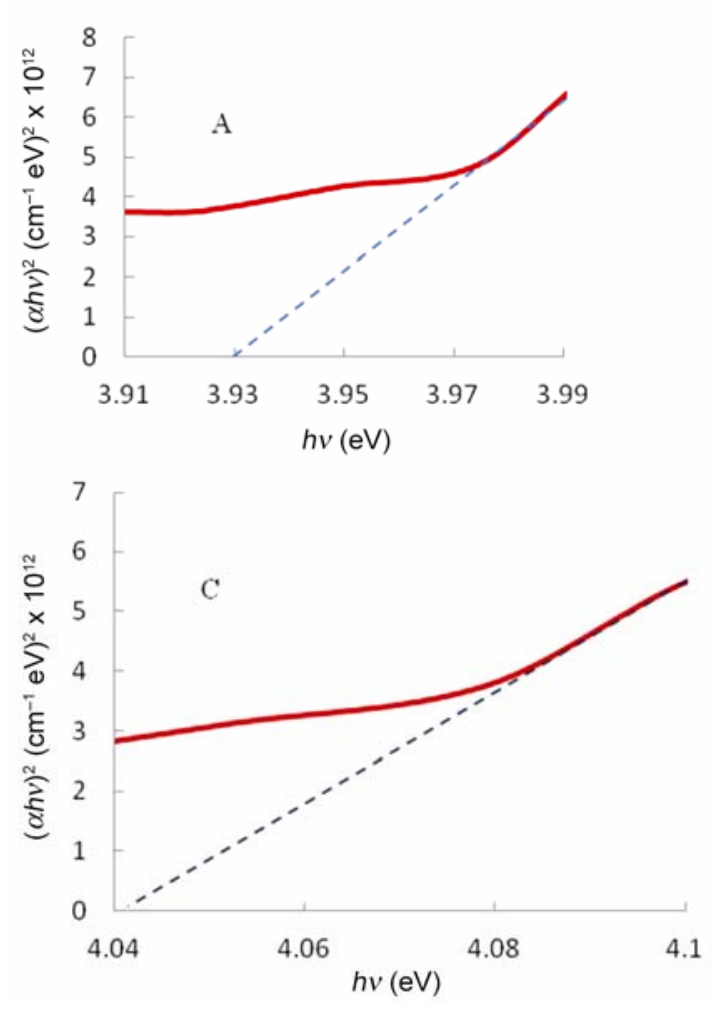
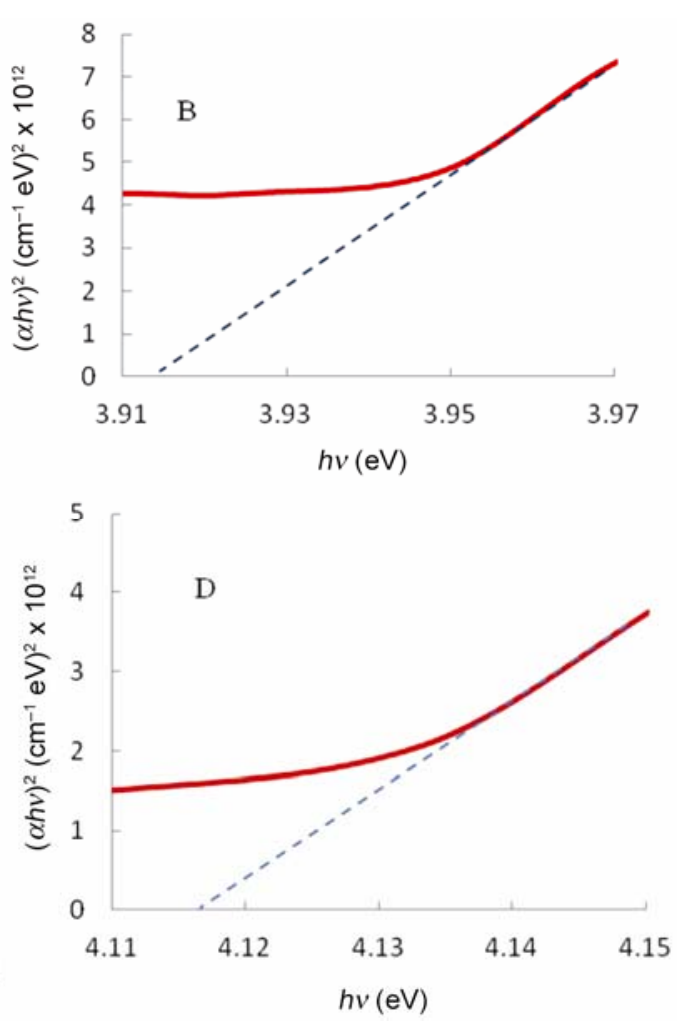

Figure 3. Relation between $(\alpha h v)^{2}$ and $h v$ of $\mathrm{SnO}_{2}$ for oxidation temperatures: $300{ }^{\circ} \mathrm{C}(\mathrm{A}), 350{ }^{\circ} \mathrm{C}(\mathrm{B})$, $400{ }^{\circ} \mathrm{C}(\mathrm{C})$ and $450{ }^{\circ} \mathrm{C}(\mathrm{D})$.

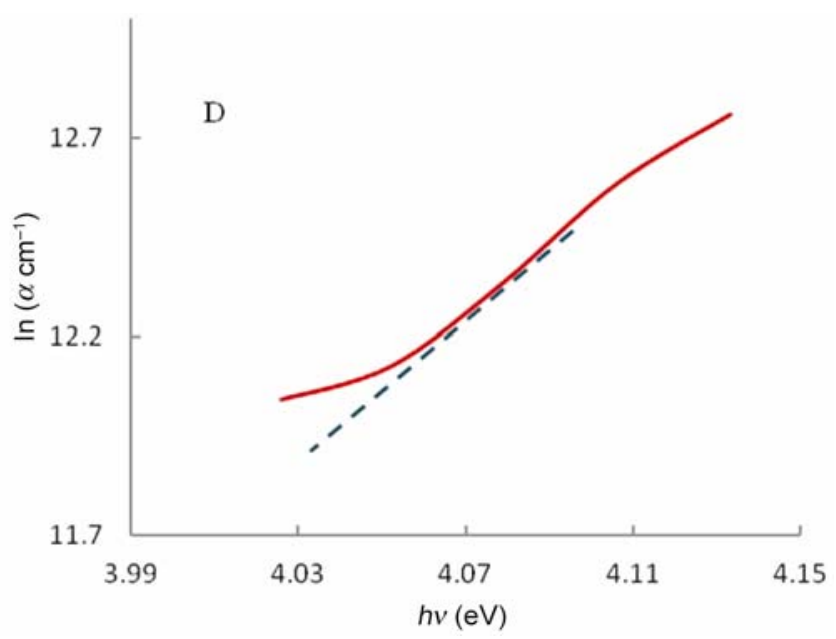

Figure 4. Plot and linear fit of $\ln (\alpha)$ against $h v$ for sample D, oxidized at $450{ }^{\circ} \mathrm{C}$.

suitable $\mathrm{SnO}_{2}$. In addition, the wavelength which these $\mathrm{SnO}_{2}$ films start to transmit, varies with annealing temperature, on the other hand, higher temperatures cause the transmittance to start at lower wavelengths.

The values of the optical bandgap of samples after annealing, was found from the plots of $(a h v)^{2}$ vs $h v$ and finding the intercepts with the energy axis. The optical band gaps varied slightly between 4.05 and $4.17 \mathrm{eV}$. The obtained values show increase of $E_{\mathrm{g}}$ slightly with temperature which is consistent with the results of transmittance; from figure 6 , it is observed that following the annealing, a shift towards the higher transmittance was obtained for all the samples. By considering the relation between the absorption coefficient and photon energy, the above results are verified. Figure 7 shows the relation between $\alpha$ and $h v$ for thin films C and D as an example. From figure 7 , it is clear that after annealing, the absorption coefficient had significantly reduced and this is due to higher oxidation temperature, but it should be noted that variation of $\alpha$ for sample $\mathrm{C}$ is more noticeable than sample D.

As mentioned before, one can use (3) to find the Urbach energy of a semiconductor, but according to Urbach-Martienssen rule, at higher temperatures specially when annealing is used, this equation is modified as the following relationship (Pana and Fu 1999; Klingshirn 1997)

$$
\alpha(h \nu, T)=\alpha_{0} \frac{E-E_{0}}{E_{\mathrm{u}}(T, X)} .
$$

where $E$ is the photon energy, $\alpha_{0}$ and $E_{0}$ are constants, which can be determined from the dependencies of $\ln (\alpha)$ on $h v$ measured at series of temperatures. Parameter $\mathrm{X}$ appearing in (4) is a measure of the degree of structural disorder of the material, as introduced by Cody et al 


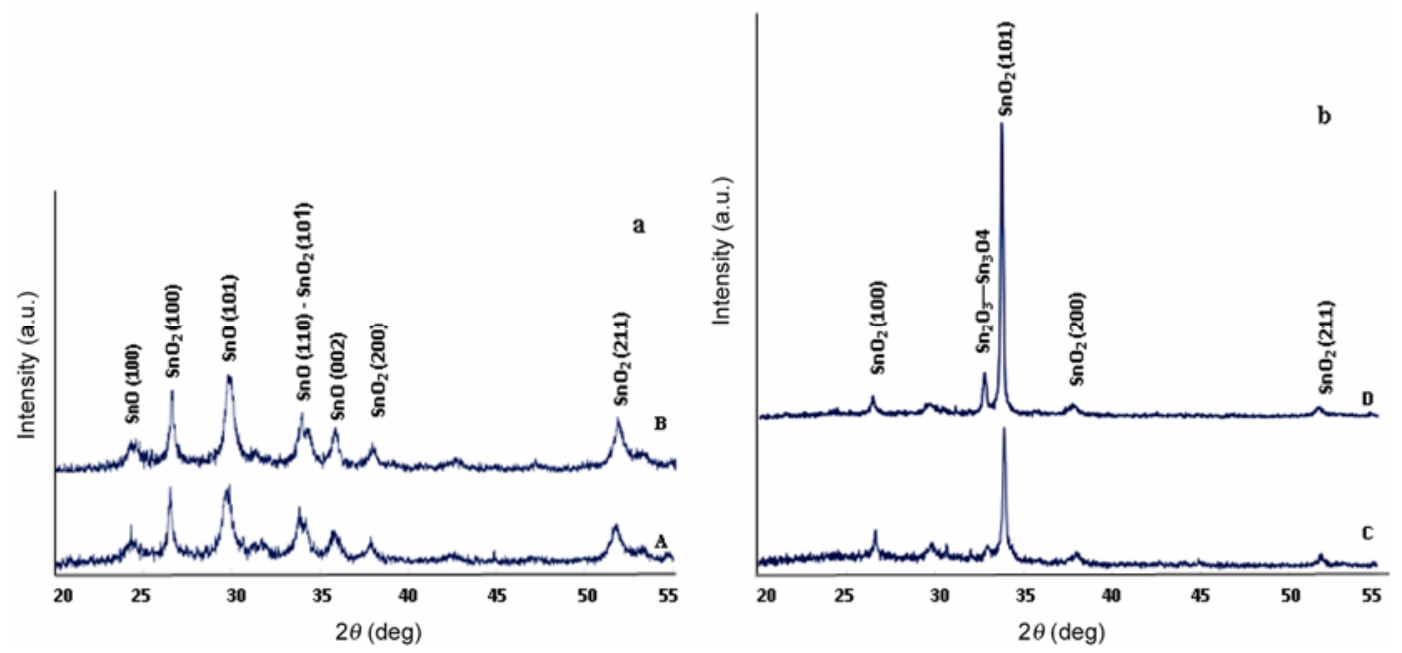

Figure 5. X-ray diffraction patterns of $\mathrm{SnO}_{2}$ thin films oxidized at temperatures: (a) $300{ }^{\circ} \mathrm{C}$ (A), $350{ }^{\circ} \mathrm{C}$ (B) and (b) $400{ }^{\circ} \mathrm{C}$ (C) and $450{ }^{\circ} \mathrm{C}(\mathrm{D})$.
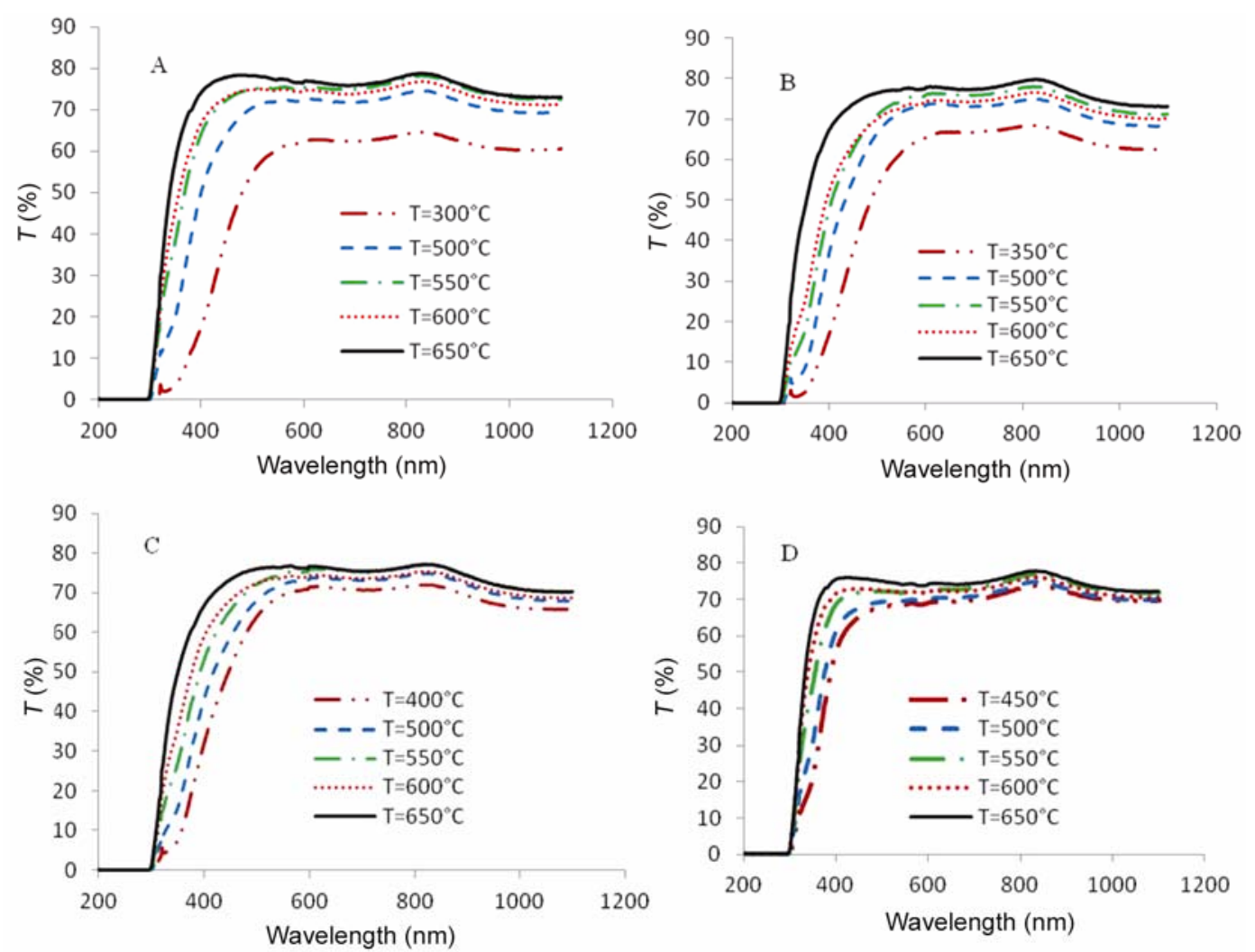

Figure 6. Optical transmittance of samples A, B, C and D for annealing temperatures 500, 550, 600 and $6500^{\circ} \mathrm{C}$.

(1981). In some literatures $E_{0}$ is considered as the energy of the lowest free exciton sate at zero lattice temperature (Biljana Pejova 2010), whereas some researchers believe that $E_{0}$ is comparable to the bandgap energy at zero temperature (Abay et al 1999). Usually, the Urbach energy can be split into two components; a temperature dependent
$\left(E_{\mathrm{u}}(T)\right)$ and a temperature-independent $\left(E_{\mathrm{u}}(X)\right)$ term (Biljana Pejova 2010)

$$
E_{\mathrm{u}}(T, X)=E_{\mathrm{u}}(T)+E_{\mathrm{u}}(X) .
$$

In (4), the extrapolations of those lines for various temperatures usually converge at a point $\left(E_{0}, \alpha_{0}\right)$, called the 
'convergent point'. This empirical rule was established by Urbach (1953) for silver halides (indirect bandgap) and found by Martienssen (1957) for alkali halides (direct bandgap). Therefore, it is called 'Urbach's rule' or 'Urbach-Martienssen's rule' and absorption tails obeying this rule are called 'Urbach-Martienssin's (U-M's) tails (Abay et al 1999). By extrapolating the lines belonging to temperatures 550, 600 and $650{ }^{\circ} \mathrm{C}$ for sample D, the $E_{0}$ and $\alpha_{0}$ of $\mathrm{SnO}_{2}$ was found to be $4.27 \pm 0.01 \mathrm{eV}$ and $8.9 \times 10^{5} \mathrm{~cm}^{-1}$, respectively (figure 8). Melsheimer and Ziegler (1985) have reported the values of $4.7 \mathrm{eV}$ and $1.9 \times 10^{5} \mathrm{~cm}^{-1}$ for convergent point of $\mathrm{SnO}_{2}$. The difference between the two results might be due to the following reasons: (a) Melsheimer and Ziegler (1985) considered $(\alpha h v)^{1 / 2}$ and $(\alpha h v)^{1 / 3}$ to determine the $E_{\mathrm{g}}$. (b) They used the spray pyrolysis method to produce $\mathrm{SnO}_{2}$ thin films. (c) To obtain the value of $E_{\mathrm{u}}$, considering $\ln (\alpha)$ against $h v$, usually the area where photon energy is smaller than $E_{\mathrm{g}}$, is selected, whereas Melsheimer and Ziegler picked the region with $h v>E_{\mathrm{g}}$.
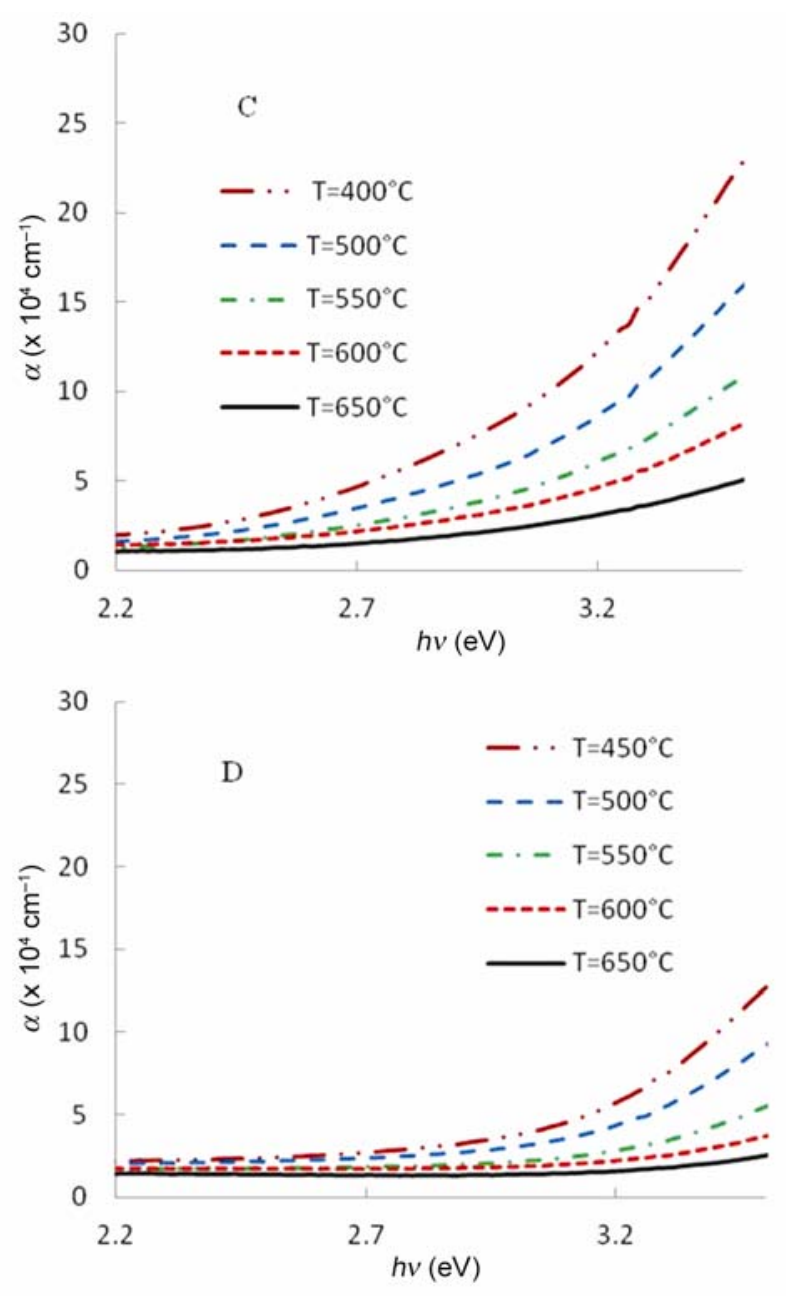

Figure 7. Relation between $\alpha$ and $h v$ of samples $\mathrm{C}$ and D for annealing temperatures $500,550,600$ and $650{ }^{\circ} \mathrm{C}$.
In order to obtain the width of the Urbach tail for $\mathrm{SnO}_{2}$, the plot of $\ln (\alpha)$ against the photon energy was plotted and the values of $E_{\mathrm{u}}$ for layers were determined as the inverse slope of linear portions of the curves. The results showed decreasing of $E_{\mathrm{u}}$ to the range of 70 $90 \mathrm{meV}$ for the samples which indicates the reduction in the $E_{\mathrm{u}}$ of the $\mathrm{SnO}_{2}$ as a consequence of heating. This reduction implies the dependence of $E_{\mathrm{u}}$ on the thermal disorder of the materials, means that according to (5), heating the samples causes reduction of temperaturedependent component of the Urbach energy $\left(E_{\mathrm{u}}(T)\right)$.

To investigate the morphology of film surfaces, samples were analysed with AFM image in latest stage of annealing $\left(650^{\circ} \mathrm{C}\right)$. Figure 9 shows AFM image of thin films A, B, C and D. The obtained values for rms roughness are found to be $32,30 \cdot 6,29 \cdot 7$ and $24.5 \mathrm{~nm}$ for samples

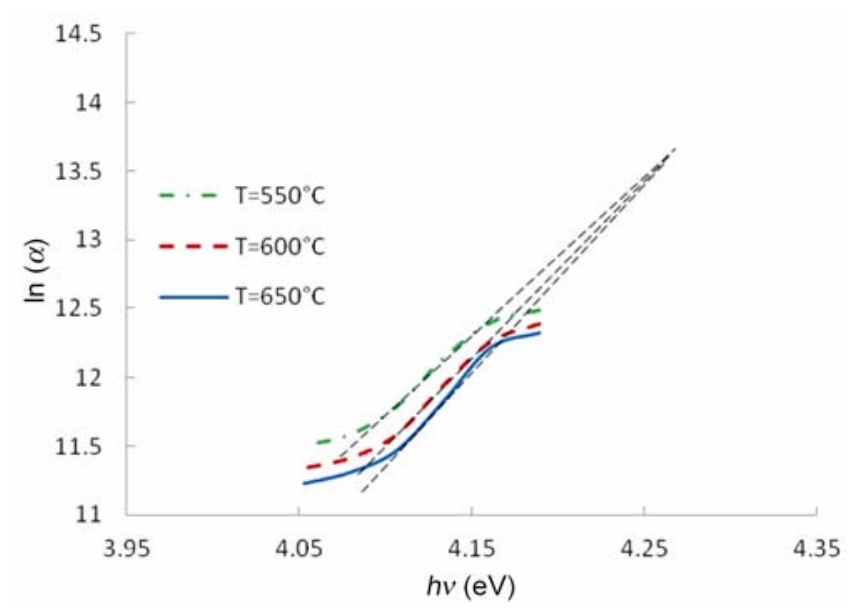

Figure 8. Logarithm of absorption coefficient vs photon energy and convergent point for sample $\mathrm{D}$, annealed at different temperatures 550,600 and $650{ }^{\circ} \mathrm{C}$.
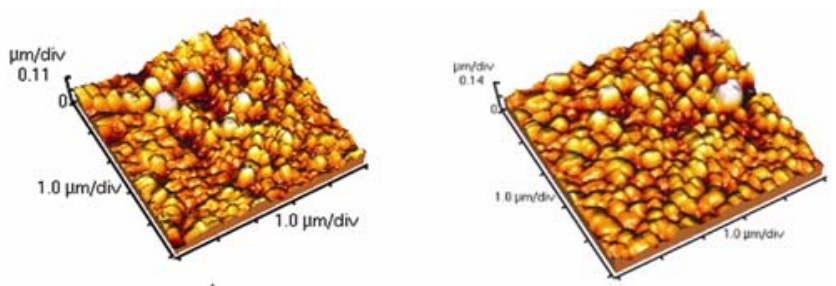

A

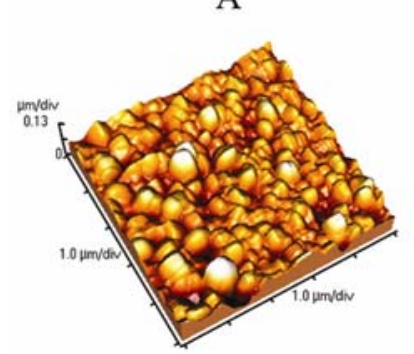

B

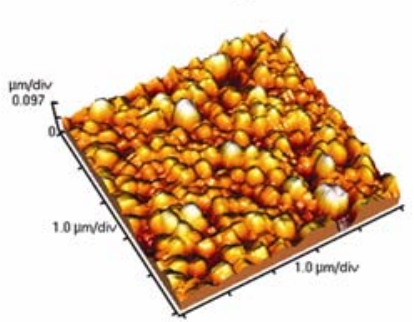

Figure 9. AFM images of samples A, B, C and D annealed at temperature $650{ }^{\circ} \mathrm{C}$. 
$\mathrm{A}, \mathrm{B}, \mathrm{C}$ and $\mathrm{D}$, respectively. These values show that although the films were annealed under similar conditions, their roughness is not the same because of the different oxidation temperatures. One can find a relation between roughness and the Urbach energy and XRD studies of the samples by considering that higher oxidation temperature produces a layer with lesser crystal disorders, low roughness and more crystallinity.

\section{Conclusions}

The optical and structural properties of tin oxide films were investigated. These samples $\left(\mathrm{SnO}_{2}\right)$ were produced after deposition of $100 \mathrm{~nm} \mathrm{Sn}$ on glass substrate by magnetron sputtering method, followed by thermal oxidation at various temperatures. Higher oxidation temperature resulted in more transmittance and lower absorption. The optical bandgap energy increased with temperature, while the Urbach energy showed reduction. The reduction of $E_{\mathrm{u}}$ is related to lesser crystal defects in the samples and this was verified by XRD results. The XRD patterns depicted that at higher oxidation temperatures (400 and $450{ }^{\circ} \mathrm{C}$ ), a polycrystalline film with sharper peaks (larger grain size) with preferred orientation of (101) produced. After annealing the samples $\left(\mathrm{SnO}_{2}\right)$, the optical bandgap increased slightly (from 4.05 to $4 \cdot 17$ ). Reduction of the Urbach energy after annealing implies the dependency of $E_{\mathrm{u}}$ on the thermal disorder of the material, which means that heating of thin films caused reduction of temperature-dependent part of the Urbach energy $\left(E_{\mathrm{u}}(T)\right)$. The values of rms roughness show that although samples were annealed at the same temperatures, the layers which are oxidized at higher temperatures, achieved less surface roughness. These results are in line with results of $E_{\mathrm{u}}$ which were smaller for samples with higher oxidation temperatures, and consequently less defects.

\section{Acknowledgements}

The authors gratefully acknowledge Arak University and also Iran Nanotechnology Initiative Council for the financial support during this research.

\section{References}

Abay B, Guder H S, Efeoglu H and Yogurtcu Y K 1999 J. Phys. D: Appl. Phys. 322942

Biljana Pejova 2010 Mater. Chem. Phys. 119367
Carlson D E 1975 J. Electrochem. Soc. 1221334

Choi W K, Sung H, Kim K H, Cho J S, Choi S C, Jung H J, Koh S K, Lee C M and Jeong K 1997 J. Mater. Sci. Lett. 16 1551

Cody G D Tiedje T, Beles B A, Brooks B and Goldestain Y 1981 Phys. Rev. Lett. 471480

Goetzberger A and Hebling C 2000 Sol. Energy Mater. Sol. Cells 621

Jochan Joseph, Varghese Mathew and K E Abraham 2007 Chinese J. Phys. $\mathbf{4 5}$

Kane J, Scweizer H P and Kern W 1976 J. Electrochem. Soc. 123270

Khan A F, Mehmood M, Rana A M and Bhatti M T 2009 Appl. Surf. Sci. 2558569

Kim H and Laitinen H A 1975 J. Am. Ceram. Soc. 5823

Kim H, Pique A, Horwitz J S, Mattoussi H, Murata H, Kafafi Z H and Chrisey D B 1999a Appl. Phys. Lett. 743444

Kim H, Gilmore C M, Pique A, Horwitz J S, Mattoussi H, Murata H, Kafafi Z H and Chrisey D B 1999b J. Appl. Phys. 866451

Klingshirn C F 1997 Semiconductor optics (Berlin: SpringerVerlag)

Lehmann H W and Widmer R 1975 Thin Solid Films 27359

Li C, Li X C, Yan P X, Chong E M, Liu Y, Yue G H and Fan X Y 2007 Appl. Surf. Sci. 2534000

Martienssen H W 1957 Phys. Chem. Solids 2257

Matthias Batzill and Ulrike Diebold 2005 Prog. Surf. Sci. 79 147

Melsheimer J and Ziegler D 1985 Thin Solid Films 12935

Nelli P, Faglia G, Sverbeglieri G, Cereda E, Garbetta G, Dieguez A, Rodriguez A R and Morante J R 2000 Thin Solid Films 249371

Pana X Q and Fu L 2001 J. Appl. Phys. 896048

Ryzhikov A S, Vasiliev R B, Rumyantseva M N, Ryabova L I, Dosovitsky G A, Gilmutdinov A M, Kozlovsky V F and Gaskov A M 2002 Mater. Sci. Eng B96 268

Rohatgi A, Viverito T R and Slack L H 1974 J. Am. Ceram. Soc. 57278

Shadia J Ikhmayies, Riyad N and Ahmad Bitar 2011 Phys. Scr. 84055801

Span S, Teng X M, Fan H T and Li G H 2006 J. Appl. Phys. A.

Sreetama Dutta, Chattopadhyay S, Sarkar A, Mahuya Chakrabarti, Sanyal D and Jana D 2009 Prog. Mater. Sci. 5489

Sung Uk Lee, Jin-Hyo Boo and Byungyou Hong 2011 Jpn. J. Appl. Phys. $5001 \mathrm{AB} 10$

Sunita Mishra, Ghanshyam C, Nathai Ram, Satinder Singh, Bajpai R P and Bedi R K 2002 Bull. Mater. Sci. 25231

Urbach F 1953 Phys. Rev. 921324

Varghese O K and Malhotra L K 2000 J. Appl. Phys. 87 7457

Watanabe H 1970 Jpn. J. Appl. Phys. 91551

Yu P Y and Cardona M 1999 Fundamentals of semiconductors (Berlin: Springer-Verlag) 2nd ed. 